\title{
Visualising learning goals with the Quail Model
}

Luca Botturi

Università della Svizzera italiana

This paper introduces the Quail Model, a device for the classification and visualisation of learning goals. The model is a communication tool that can smoothen the discussion within a course design team, support shared understanding, and improve decision making. Its theoretical background mingles contributions from instructional design (Bloom, Gagné, Merrill) with the insights of an author of philosophy (Lonergan). The paper presents a literature review, the Quail Model and some examples. Reference to demonstration application is also provided.

\section{Introduction}

The statement of learning goals is one of the most important and deciding moments of the instructional design process, as they are like a compass indicating the desired destination, the expected final outcome of the educational activity.

This paper presents a novel tool for the visualisation of learning goals, called the Quail Model. Three claims by Anderson \& Krathwohl (2001) may provide the best introduction, as they define the perspective in which the Quail Model was developed:

1. The focus is not on the verbal expression of goals, rather on their definition and understanding by designers.

2. Classifying goals may help to face four issues in instructional design (ID): (a) the learning issue, or what should be learnt? (b) the instruction issue, or how to teach it? With what tools and media? (c) the assessment issue, or how to assess the achievement of goals? And (d) the alignment issue, or how can all the components of an educational environment be consistent?

3. Goals should be defined within a context, expressed by the curriculum the grade, etc. The interpretation and use of a model may vary according to it. 
An architect designing an apartment can control the whole process and also the actual construction (excluded cost constraints or other external limitations): if the owner in the end is not satisfied, this should be imputed to a misunderstanding in the requirement analysis - the architect's image of the final result was not shared by the owner. The situation gets more complex in education. First, instead of one owner, there are stakeholders (such as a boss who wants employees to be trained, or a Faculty Committee planning a new curriculum) and learners (who would like anything but a training session... - or who are willing to start their university experience). Moreover, given correct goals corresponding to the learner's and stakeholder's expectations, their achievement is a result of the interaction between the planned educational activity and the learners, and is not completely up to the designer's will and competence. But let's go one step further: differing from other design activities, learning goals are not easy to express as they concern mental states, non-observable events.

These are only some of the reasons why learning goals are one of the major topics in ID. A large part of the literature suggests that goals should be analysed and decomposed before expressing them verbally or mapping them on any kind of visualisation, during the instructional analysis phase (cf., Dick \& Carey, 2001). Nevertheless, and this is the point, the instructor, the subject expert and the designer think in terms of high level goals. They can afterward be analysed and decomposed - but this is a technique, useful for the further design steps, yet unnatural. A teacher does not only think of behaviours, but also of ways of thinking, judging, perceiving values, interests, etc. This is why I believe a tool for representing high level goals before instructional analysis may be a powerful design support. The Quail Model introduced in this paper is not a tool for instructional analysis, but a visualisation device for enhancing team communication about goals. As such it can be used both before and after decomposing the goals: the representation of lower level goals does not present any particular difficulty. Entry competencies could be also represented on the Quail Model, thus allowing determining the learning gap.

The Quail Model was conceived as a representation device that instructional designers may use in order to share their ideas with instructors, subject matter experts, media designers, web programmers, or anyone who is part of the instructional development team.

The basic assumption underpinning the Quail Model is that in order to achieve high quality instructional experiences, learning goals should be clearly stated, thoroughly understood and shared by the whole design team. Moving from that assumption, the Quail Model relies on the hypothesis - which is actually a truism - that being able to see goals can 
enhance understanding and foster discussion. The idea is to provide a visual tool for it. Consequently, this work is not concerned with the verbal expression of (behavioural) goals, nor directly with assessment and evaluation.

Section 2 presents a literature review about the definition and classification of goals. Given the extension of contributions on this topic in the last decades, it does not have any claim of exhaustiveness, but it is functional for the development of the Quail Model, presented and discussed in the Section 4. Section 3 is devoted to introducing the work of Bernard J. Lonergan, which forms the main theoretical background of the model. Section 5 provides some examples, while Section 6 reports feedback from instructors and designers who used the model for their design practice.

Finally, Section 7 draws some conclusions and scenarios for further work.

\section{Visualising learning goals}

The following paragraphs present a selection of taxonomies and visual models for the description and classification of learning goals.

The general definition of learning goal is likely to be the only shared point among all the authors that dealt with the issue. A learning goal is the formulation of the expected outcome of the instruction in terms of acquired knowledge and competencies. The correct formulation of a goal should take the learner perspective ("be able to draw pie charts"), leaving aside the instructor's perspective ("show students how to draw pie charts") and the activity perspective ("discuss some pie charts with the students and let them work on a small data set on their own"). A goal should therefore describe the desired final status of the learner with respect to the changes developed during the learning activity (Gronlund, 1995). A more precise definition distinguishes goals - high level learning achievements concerning a whole course or module - from objectives - low level learning achievement concerning a single lecture or learning activity. Several objectives can be therefore defined for each goal; for example the objectives "Define leadership", "Recall examples of different organisations", or "Distinguish companies from institutions" are a specification of the goal "Provide a critical definition of organisation".

According to the perspective introduced above, the Quail Model only deals with goals, and is not concerned with the expression of objectives.

\section{Bloom's taxonomy of learning goals}

Starting almost 50 year ago, Bloom's team collected school and college syllabi and developed a general classification of the goals they contained 
(Bloom et al., 1956; Bloom et al., 1964). The idea was to help the US education system to improve the quality of instruction with a tool that could support the discussion about "what we want to achieve".

They distinguished two domains of learning, described in two handbooks: (a) the cognitive domain, which includes intellectual knowledge and cognitive skills; and (b) the affective domain, which includes values, interests, attitudes, opinions, appreciations, values, emotional sets and what is called today emotional intelligence.

Each domain represents a specific type of knowledge (cognition/affective skills), and proposes different levels that could be reached. The taxonomy is hierarchical (levels increase in difficulty/sophistication) and cumulative (each level builds on and subsumes the ones below). Due to the extension of the taxonomy and the limitation of space, the complete list of knowledge levels is not reported here.

Bloom divides the cognitive domain into six main levels that do not form a continuum. The first one, called knowledge in the handbook, but often quoted as recall, includes types of knowledge, while other levels (comprehension, application, analysis, synthesis, and evaluation) include cognitive abilities. Notice that the final step of cognition, evaluation, has actually a strong relationship with the affective domain. The authors indeed declare the tight connection between the two levels, but do not provide a complete integration.

Affective goals have a slower attainment than cognitive ones, and are therefore more difficult to observe. The affective domain is structured on five levels: receiving, responding, valuing, organisation, and characterisation. Like the cognitive domain, they are sequential, but unlike it, they represent a continuum in a process of internalisation of values and practices, or in the assimilation of a culture. The analysis and statement of affective goals are more difficult than of cognitive ones, although several goals in K-12 and high school curricula belong to this domain. Lee \& Merrill (1972) present an interesting discussion of affective goals.

\section{Gagné's taxonomy of learning outcomes}

Gagné (1992) proposed another classification schema for learning goals. His taxonomy is articulated in five categories (also called domains) of knowledge. Interestingly, the choice of Gagné is orthogonal with Bloom's:

${ }^{1}$ Bloom's research group did not develop in depth categories for a third domain they identified, the psychomotor domain, claiming lack of experience in teaching these skills. Several authors proposed a completion, eg., Harrow (1972). 
Gagné's domains actually represent different types of knowledge (namely, verbal information, intellectual skills, cognitive strategies, attitudes, and motor skills), and not levels.

Gagné \& Merrill (1990) developed the idea of learning enterprise (which was also in Gagné, 1985): the combination of different types of knowledge into a more general expertise. The authors claim the necessity of expressing complex goals that reflect practice in the real world, in order to enhance transfer. Learning enterprises are defined within the context of a scenario, and are achieved through the provision of a general schema integrating the different knowledge types into one whole and specifying the connections between them. The idea of complex goals has consequences on the practice of design: "Whereas current instructional design methodology focuses on components such as generalities and examples, which are geared for promoting acquisition of single goals such as concepts or procedures, a consideration of enterprises as integrated wholes may lead to a future focus on more holistic student interaction for "transactions'." (Gagné \& Merrill, 1990, p. 29)

\section{The performance-content matrix}

In the context of his Component Display Theory (CDT - Merrill, 1983 Merrill, 1994), Merrill proposed a two dimensional classification of learning outcomes (Figure 1). Merrill identified four types of learning outcomes (or content), partially overlapping with the previous two taxonomies, namely:

1. Facts: declarative knowledge.

2. Concepts: the definition of categories and mental tools for the simplification and understanding of experience.

3. Procedures: sequences of rules and actions for accomplishing a task in a given situation.

4. Principles: general rules that can guide heuristic action.

Interestingly, Merrill proposed a new pattern, describing three levels of attainment of goals, called performances:

1. Remember: recalling a fact, concept, procedure or principle (know that "the Capital city of Ticino is Bellinzona" but also that "for cooking pasta, first let water boil"). Merrill distinguished remember-instance and remember-general.

2. Use: applying some abstraction to a specific case, such as using a concept, applying a procedure or a principle ("if today is public transportation strike, do not look for a bus"; not just knowing what driving safely means, but actually driving that way. 
3. Find: being able to derive or invent new concepts, modify or create new procedures for a new set or subset of problems, or define new

principles (given the general principles of instructional design, adapt

them to the specific learning and institutional context; or extend the classification of interactive artifacts in order to include new elements).

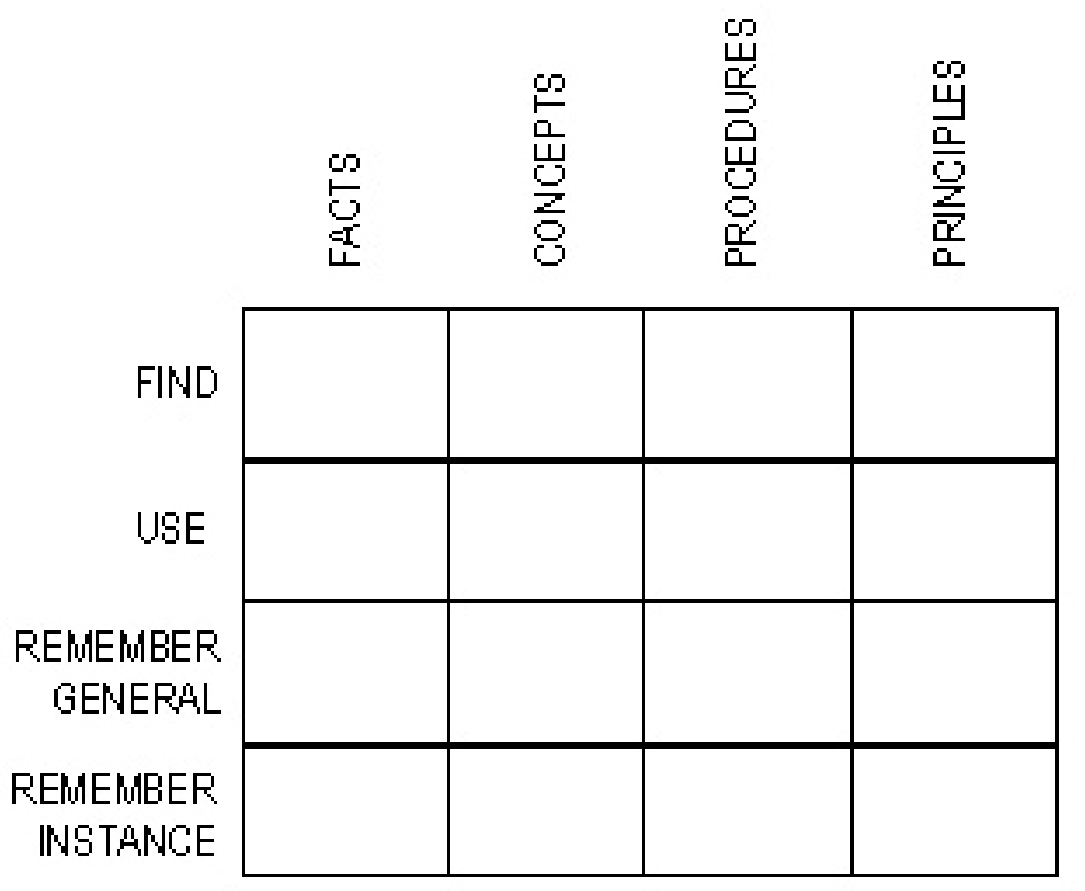

Figure 1: Merrill's performance-content matrix

Within the CDT theory, the performance-content matrix is linked to the specification of test items and to a discussion of the very idea of subject matter. Merrill's grid has the advantage of being straightforward (it defines only 4 content types and 3 performance levels) and at the same time rather precise, with 12 possible distinct outcome areas. The simple fact that it is a matrix - a visual representation - increases its usability. It will be reprised and merged with other contributions in the Quail Model.

\section{Bloom's taxonomy revised}

Continuous and widespread citation of Bloom's taxonomy attested to its perceived value over time, and prompted two of the original authors to produce a revision, and to create a new tool for classifying learning goals, in the form of a two dimensional grid (Anderson \& Krathwohl, 2001). 
The emphasis in Anderson and Krathwohl's work is on classifying rather than expressing goals. This was indeed the proper goal also for Bloom's, Gagné's and Merrill's works, but a great part of the work of the later interpreters focused on behavioural verbs and "correct" wording.

The vertical dimension of the grid (Figure 2) represents the knowledge dimension, i.e. the type of knowledge at stake; the horizontal represents the cognitive dimension, i.e. the cognitive process to be performed.

\begin{tabular}{|c|c|c|c|c|c|c|}
\hline \multirow{2}{*}{$\begin{array}{l}\text { THE } \\
\text { KNOWLEDGE } \\
\text { DANENSSON }\end{array}$} & \multicolumn{6}{|c|}{ THE COGHITIE PROCESS DIKENSSON } \\
\hline & REMEMBER & UNDERSTMND & APPLY & AN,OLYZE & EVQLUATE & CRE,PTE \\
\hline $\begin{array}{l}\text { FACTUAL } \\
\text { KNOUULEDGE }\end{array}$ & & & & & & \\
\hline $\begin{array}{l}\text { CONCEPTUQL } \\
\text { KNOINLEDGE }\end{array}$ & & & & & & \\
\hline $\begin{array}{l}\text { PROCEDUR,QLL } \\
\text { KNO INLEDGE }\end{array}$ & & & & & & \\
\hline $\begin{array}{l}\text { WETA-COGNITIVE } \\
\text { KNO WILEDGE }\end{array}$ & & & & & & \\
\hline
\end{tabular}

Figure 2: Anderson \& Krathwohl's grid

Interestingly, the revised taxonomy presents both the elements on which Bloom and Gagné focus: types of knowledge and skills, and a representation of the cognitive process. Although the categories are similar to the original taxonomy, their arrangement on a two dimensional grid and the distinction of the knowledge and cognitive process dimensions make it a new and powerful tool.

Anderson and Krathwohl propose to chart on their grid not only goals, but also activities (in relation to the specific goals addressed) and assessment (in relation to what is being actually assessed), in order to control the alignment or consistency of the whole instruction.

\section{Learning as intentional activity and a process}

Bernard J. Lonergan, a philosopher, economist and scholar in theology, proposed a synthetic view of the learning process, indeed novel to the field of instructional design. The choice of his description of cognition as the backbone of the Quail Model also responds to the natural interdisciplinary character of this field. 
Lonergan proposed an articulation of the learning process on three levels: experience, understanding and judgment (Lonergan, 1990; for a synthetic introduction to the model, cf. Lonergan, 1988). According to his view, our drive to know proceeds from personal experience: we want to know, as we express wonder as questions about the objects and situations we meet and we live by, and these questions are the primary sparkle of knowledge. The second step in learning is understanding, which means discovering the intelligible pattern in the image of the object. As analogy, it is the work of the detective or of the scientist, who sees a situation - a murder or a natural phenomenon - and tries to select the relevant features in order to build a complete model, a unitary vision of its causes. The third level is the level of judgment, in which objects of thought are transformed into objects of knowledge. This happens through the act of judging, or assenting: recognising that a certain understanding of a situation or a certain fact is true and corresponds to reality. This is the moment in which critical thinking comes into play, creating room for self commitment and behavioural change.

The process of learning through the three levels of experience, understanding and judgment can be analysed more finely through the activities in progress at each level, as represented in Figure 3.

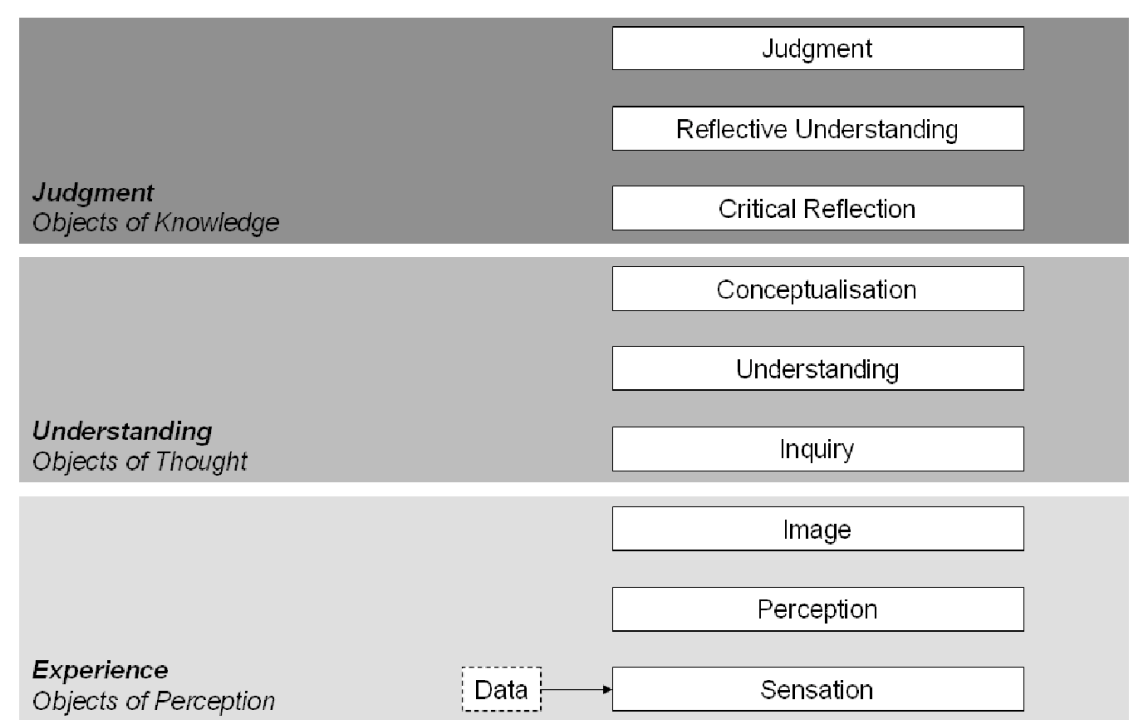

Figure 3: Activities in progress at each level in the learning process 


\section{The level of experience}

To our perception, reality is an unlimited amount of data, where data means all perceptible elements: writing and pictures as well as smells and heat variations. Data is what can be owned, possessed and transmitted, once they have been represented somehow, as ink on paper or as electrical impulses. Data in themselves do not constitute knowledge, but they are the first and necessary step in cognition: sensations are our impact with data.

Sensations are filtered by perception, i.e. the active process of focusing on sensations and organising them in our consciousness. Perception is active: previous knowledge, conceptions and misconceptions, expectations and fears influence it, for example as in the famous research of New Look by Bruner \& Goodman (1947; 1949). Cognitive science and psychology are the disciplines nowadays more concerned with this level.

The perception of data gathered through our senses is actively organised in our minds as image, or mental representation. The generation of a correct mental image, suitable to understanding, is one of the main concerns for the teacher. According to Lonergan, the image is our way of representing the object of experience to our inner flow of consciousness, and is the starting point for understanding.

\section{The level of understanding}

In order to become information, data have to be interesting, they must "have to do" with the perceiver: relevance is what draws our attention, what directs our flow of consciousness to that specific object and to its image in the mind. This happens in the form of an inquiry, asking "Why?", "What is it?", or "How often?"

Understanding, or insight, is the process through which we answer questions of this kind, and it means to recognise necessity or "the must" in the object, to grasp it "as it is". Let us imagine a child has to learn what a hexagon is: the teacher shows the child a drawing of an orange hexagon with a red border. Then the child is helped drawing a second shape just with a red line - and here he understands, or can understand the situation: a hexagon is a planar closed shape with six sides and six angles, independent of line color or filling. Notice that the proper verbal expression is not a condition for understanding. Understanding is not the formation of a concept, but the comprehension of the instance situation, 
the moment in which we feel we are grasping it. The act of understanding is active - teaching also means stimulating and fostering this process ${ }^{2}$.

The formation of a concept, or conceptualisation, is the next step: a generalisation and a formulation of the understanding. "When we move to conception or formulation, the matter is more complex, since we form concepts in many ways .... By your insight into the image you are able to formulate the conditions, the elements in the image, necessary to having the insight" (Lonergan, 1990, p. 165). A concept is formed as soon as we think of the general case of which our specific object is an instance, like when proceeding from the understanding of a hexagon to its definition, which covers all possible cases. In web design, it is the difference between a good solution to the commissioner's problem - the right idea, an insight - and a sound model, with definitions and procedures, for developing web sites. It is likely that a good intuitive designer can propose a portal-like design, or a collection-like design even without having a clear conceptualisation of the distinction between portal and collection in general. Concepts can exist only by means of a (verbal) language; this is why linguistic expression is a powerful tool for helping students in shaping their own concepts. Teaching is in fact a matter of communication, and from this point of view, language can be considered as a set of formulated insights that we receive from our tradition.

\section{The level of judgment}

The main novelty of Lonergan's approach is indeed the explicit introduction of a third level in the cognitional process, where insights, formulations and concepts are transformed into objects of knowledge. After experience has been understood in the instance situation (insight), and concepts have eventually been formed as a formulation of the general case, a new kind of question arises, as reflection on our own thinking: "Is it really so?", "Is it true?" Critical reflection is the act through which we turn to our conceptualisation or understanding and we ask ourselves about its adequacy to experience: "Did I really get the gist of that novel?" or "Will this actually work and improve my job?"

The answer to such a question is an insight in our formulation. The method is reflective understanding: gathering evidence that our understanding and our concepts work or fit the knowledge object. Reflective understanding means moving backwards until we find some

${ }^{2}$ Lonergan also defines reverse understanding as the understanding that some question is not relevant for the situation, and that requires no further inquiry. This is of course highly relevant in scientific research, where the selection of the right question is a fundamental concern. 
(virtually) unconditioned, i.e. some verified fact or previously verified understanding or concept, that supports the appropriateness of our understanding.

This detail may become clearer through an example. A man goes out in the morning, and when he comes back finds windows broken, smoke inside the room and a terrible smell. Given the situation, he comes to an understanding and says "something has happened" - the state of the house has changed, so an event has occurred. He can think further: "somebody entered my house, stole my things and lit a fire". This is a possible understanding of the situation; but is it true? A confirmation can come only from evidence. If the man sees footsteps inside the house, which do not correspond with his own and he lives alone, he can go a little bit further in the reflective analysis: the footsteps prove without conditions that someone has been there.

Judgment is the act by which we recognise and affirm the adequacy of our understanding and conceptualisation to the situation or the type of situation encountered in our experience. Judgments are of different types according to their objects: they can be formulated on facts, insights into instance situations, generalisations or concepts, mathematical theories, common sense activities or scientific discoveries. Moreover, judgments of any type can affirm truth at different levels, from complete certainty (as judging the fact that you are now reading) to all hues of probability. The acquisition of certainty depends of course on the psychological aptitude of the learner, who can also dismiss the request of judgment and refuse to take the risk of commitment. Judgment is necessary in order to get the learners to commit to what they have learnt and eventually to change behaviour.

\section{Learning as a dynamic}

According to Lonergan, learning can start at any level: from experience, from a concept which is learnt but not understood, as it is often the case at school, from a judgment that is critically put under revision, etc. The main point is that knowledge is never complete, and completely human, if it does not involve all levels into one dynamic. Learning therefore simultaneously proceeds bottom up (from perception to judgment), and top down (from knowledge and concepts to understanding). On the other side, the concepts and previous knowledge influence our perception and understanding. The more we are interested and have a lively and deep relationship with an object, the more we will be able to improve our knowledge of it. That's why your technology addict friend always gets the idea of what is the best choice in computers much faster than you do. 
This dynamic is supported by hypotheses making and by the definition of an ideal of knowledge (Lonergan, 1990). The top down flow in fact consists mainly in defining a hypothetical arrival point for the pursued knowledge, which serves as a grade for the whole process. It is a mere representation of something we do not know - hypothetical indeed - and this exactly its value: it is a name, like the $x$ in mathematical expressions. One of the main challenges in teaching is offering a sensible, understandable and fascinating $x$ to chase in learning.

\section{The Quail Model}

The Quail Model is a representation device for visualising learning goals. The Quail Model is concerned with the cognitive and affective domains of Bloom's taxonomy (Bloom et al., 1956; Bloom et al., 1964), while psychomotor goals are not addressed here and could be hardly represented in this model.

The visualisation of goals with the Quail Model is all about practicality: it can be useful as all design team members may indicate where they are going to, and a possible way to that. From this perspective, two points deserve great care: first of all, the representation device should be consistent with the kind of goals addressed (cognitive or affective; with another model, psychomotor); secondly, the designer should be familiar with it and be conscious of - if not share - its underlying implications.

\section{An example: Teaching the brain}

The goals reported in Table 1 are taken by a 2 hour class activity for 5 th grade children about an introduction to the brain ${ }^{3}$.

Table 1: Goal statement example

\begin{tabular}{|c|l|}
\hline Tag & Statement \\
\hline G1 & $\begin{array}{l}\text { Know that we all have a brain and a nervous system as all animals (but not } \\
\text { plants and things) }\end{array}$ \\
\hline G2 & Describe a brain (macroscopic) \\
\hline G3 & $\begin{array}{l}\text { Describe the functional macroareas of the brain, and how they communicate } \\
\text { with each other }\end{array}$ \\
\hline G4 & $\begin{array}{l}\text { Know that the brain is composed by neurons. Be able to provide a simple } \\
\text { definition of neuron }\end{array}$ \\
\hline G5 & Act safely in order to avoid brain damages \\
\hline G6 & Develop interest into neuroscience, formulate questions \\
\hline
\end{tabular}

${ }^{3}$ The development of this activity was carried out within the Research Seminar Svizzera italiana in collaboration with Settimana del Cervello Ticino. 
The goals presented above in Table 1 are sketched below in Figure 4 on the Performance-Content matrix.

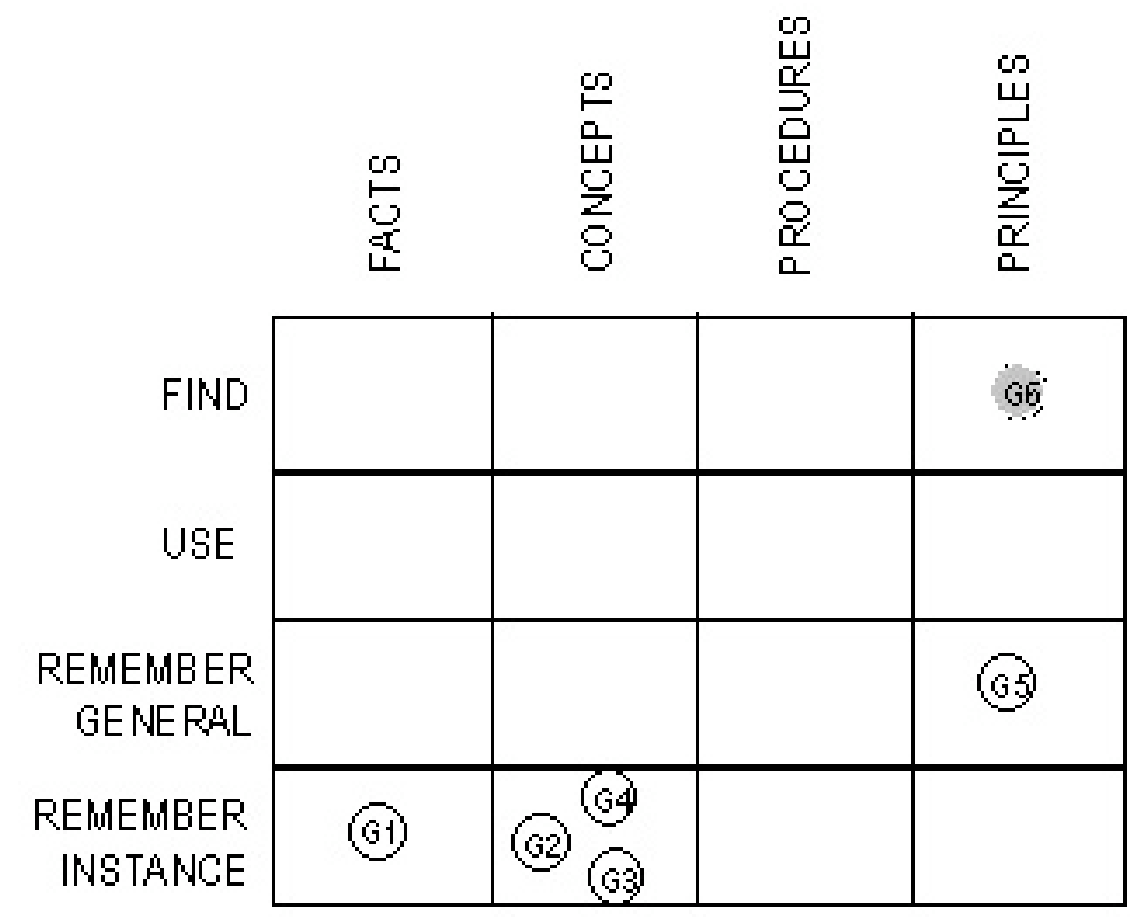

Figure 4: Example of goal visualisation on Merrill's matrix

While G1 concerns a fact (we all have a brain), G2, G3 and G4 have to do with concepts (what the brain is like, functional areas, and the neuron). G5 concerns an attitude (to act safely), which could be translated into principles to use in certain situations - although this does not fit completely. The representation of G6 (develop interest in neuroscience) is more controversial: the matrix does not have a specific space for interest it was translated into principles (a way of behaving, in a certain way: it is good to know more about it), which are open to transformation at the find level.

The same goals could be represented on the grid developed by Anderson \& Krathwohl (2001), as in Figure 5.

This grid allows the localisation of a goal in more then one cell. It happens for G3 and G4, which are split between facts to remember and concepts to understand. This reveals that those goals contain two components that 
share the same relationship existing between G1 (the fact that we have a brain) and G2 (what a brain is like). G5 was transformed into procedures (although principles grasped its essence better). The problem with G6 remains: interests do not have a proper location on the grid.

\begin{tabular}{|c|c|c|c|c|c|c|}
\hline \multirow{2}{*}{$\begin{array}{l}\text { THE } \\
\text { KNOWLEDEGE } \\
\text { DIMENSION }\end{array}$} & \multicolumn{6}{|c|}{ THE COGNITYE PROCESS DIMEASION } \\
\hline & REMEMEER & WNDEFSTAND & QPPLY & ANGQLY在 & EVIRLUUTE & CREMTE \\
\hline $\begin{array}{l}\text { FACTUML } \\
\text { KNDOOLLEDGE }\end{array}$ & 616364 & & & & & \\
\hline $\begin{array}{l}\text { CONCEPTUaL } \\
\text { KROOWLEDGE }\end{array}$ & & 636462 & & & & \\
\hline $\begin{array}{l}\text { PROCEDURQL } \\
\text { KNOWOLLDGE }\end{array}$ & & & 65 & & & \\
\hline $\begin{array}{l}\text { METQ.COGNITIVE } \\
\text { KNOWOLLEDGE }\end{array}$ & & & & & & G6 \\
\hline
\end{tabular}

Figure 5: Example of goal visualisation on Anderson \& Krathwohl grid

\section{Structure of Quail}

The Quail Model is a three dimensional grid representing the type of learning outcome, the level of knowledge and the scope ${ }^{4}$ of application. The use of three dimensions is justified by the literature review reported in the first section. Namely recall that:

1. Bloom's taxonomy levels for the cognitive domain are not continuous, but are split between knowledge and abilities. These are reported here on two different axes, as proposed by Anderson \& Krathwohl (2001).

2. The definition of the performance for a goal is here reported in the three scopes, which reprise Merrill's Performance-Content matrix (1983).

3. The distinction of cognitive and affective domains is analytically justified, but it is an unnecessary hurdle in expressing goals. Moreover a large number of goals require the simultaneous reference to both domains (Bloom et al., 1964). The Quail Model knowledge levels, taken from Lonergan's learning dynamic, are an attempt to establishing a continuum between the two of them.

${ }^{4}$ Although not completely self-evident, the term scope identifies the area or general type of activity in which the effect of the achievement of the goal should be

observable: remembering something, applying something, or generating

something new. 
4. All models reviewed missed the distinction between external knowledge objects (such as "learning the solar system planets") and self reflective learning ("perceive the relevance of literary works to one's experience"). This is included in the Quail Model with self reflective goals.

\section{Type}

The types of learning goal are taken from Gagné's classification (Gagné, Briggs \& Wager, 1992), adding interpersonal skills. Types considered are:

- Factual knowledge: declarative knowledge, know-that.

- Concepts: categories, types of objects, defined concepts, abstractions.

- Procedures: steps in a process for accomplishing a task or achieving a goal.

- Principles: guides to heuristic actions.

- Attitudes: dispositions to behave.

- Learning strategies: meta-cognitive strategies, learning to learn.

- Interpersonal skills: ways of relating to other persons, communication skills.

Complex goals can be represented grouping different types of goals into a sort of balloon.

The representation of self reflective learning, i.e. learning experiences in which the learner's self is both subject and object of knowledge (such as in "Expressing and evaluating one's idea of education") is another distinctive feature of the model. Any knowledge type can be used for self reflecting knowledge. Self reflective goals are represented with a looping arrow. The visual key for goal type representation is provided in Figure 6.

\section{Level}

The levels of knowledge are described according to Lonergan's representation of the learning dynamic (1957). The original structure has been rearranged on three points:

1. Sensation, perception and image are usually not addressed by instruction, as they are not properly cognitive levels (they come before cognition, even if they are influenced by it). They have been therefore reduced to one single step labeled experience, which concerns the consideration of a specific object and the generation of the image ${ }^{5}$.

${ }^{5}$ I think that the levels of sensation and perception should be considered for psychomotor goals, as they profoundly concern reflexes and unconscious action. 
2. The level of judgment was reduced to two levels:

a. Reflection, which is the same as Lonergan's;

b. Commitment, which includes reflective understanding and

judgment. These latter are in fact personal activities of the learners,

strictly correlated, and which can seldom be separated in practice. It was labeled commitment in order to stress that asserting the value of knowledge means recognising its importance for one's self.

3. Finally a new level was introduced, named action. Lonergan introduced it in a later work (Lonergan, 1980), with the name of responsibility, indicating the personal response to what the newly acquired knowledge requires in terms of a change in behavior.

The Quail Model represents therefore levels in the learning dynamic that describe the status and integration of knowledge within the learner's horizon. The definitions of levels are the following:

1. Experience

a. Experience: meeting, considering a possible object of knowledge, and perceiving a correct image of it, which becomes part of the learner's world.

2. Understanding

a. Inquiry: developing an interest and asking "What is it?" or "How is it?" concerning the potential object of knowledge.

b. Insight: understanding a single instance case, grasping the essence (pattern of intelligibility) of the object of knowledge as a single case.

c. Concept: through generalisation, induction and abstraction, conceiving a reusable and articulated formulation of what is understood. The generation of concepts requires a (verbal) language or means of expression.

3. Commitment

a. Reflection: parallel to inquiry, asking "Is it so?" concerning the new knowledge. Although the word reflection was used for readability, it should be understood as critical reflection.

b. Commitment: assessing the value of the newly acquired knowledge as relevant to the learner's self.

4. Action

a. Action: Including the new knowledge in the action, as integrated part of the learner's self. This means that after intelligence, freedom (or free will) should be put in motion in order to act the way one has learnt, and to realise the commitment ${ }^{6}$.

${ }^{6}$ This also raises the issue of the ethical dimension of knowledge, and therefore of teaching and learning (e.g. as responsibility of knowing something). 


\section{Scope}

The last dimension of the Quail Model considers the scope of knowledge, which describes to what extent the new knowledge is expected to influence the learner in action. The scope could be expressed as the terminal part of the sentence "I want the learners to know X in order to Y", where $X$ defines a specific couple of knowledge type and level, whereas $Y$ defines the expected result in terms of change in the learners. The metric is defined according to the performances in Merrill's matrix:

1. Remember: recall knowledge as such.

2. Use: apply knowledge to specific situations.

3. Find: exploit knowledge in order to generate new knowledge.

\section{The complete model}

The complete model, articulated in its three dimensions, is represented in Figure 6. Levels and scope form a bi-dimensional grid, while knowledge types are visualised through shapes. The goals from Table 1 could be represented as in Figure 7.
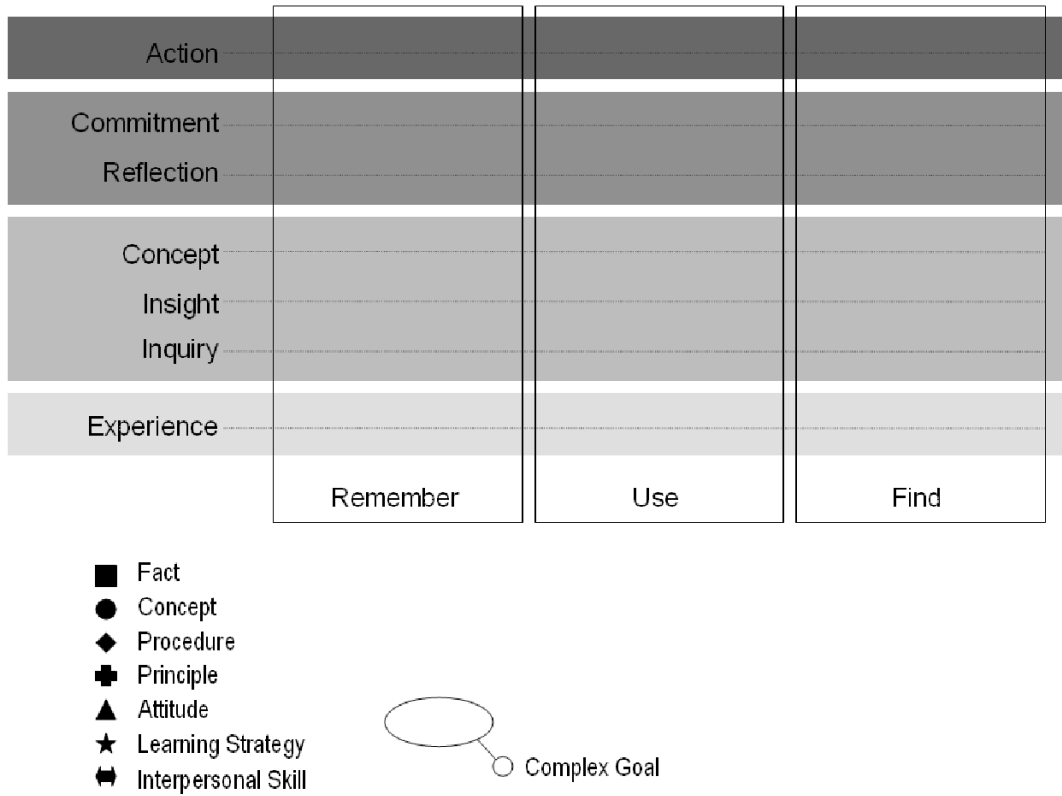

Use

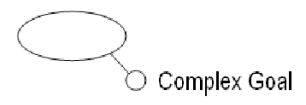

Figure 6: The complete Quail Model 


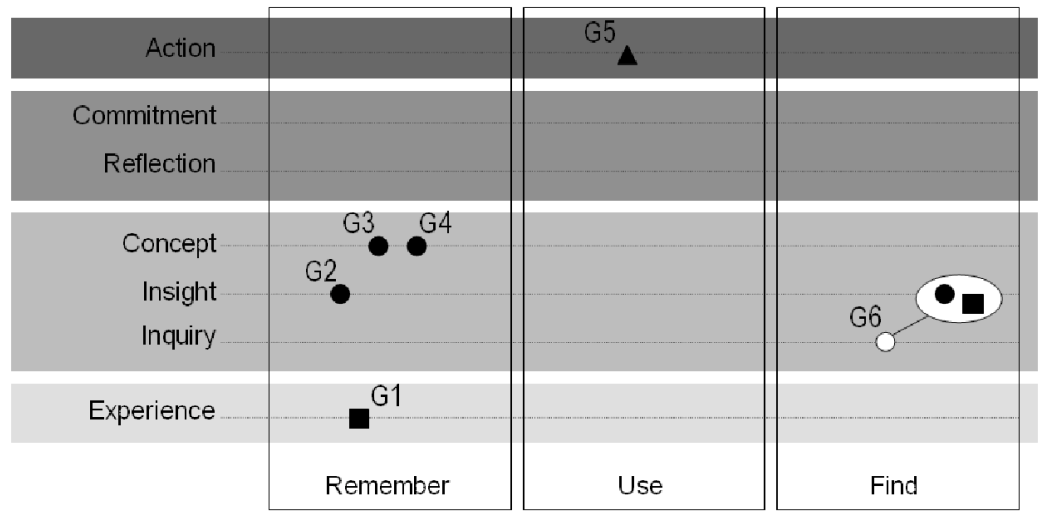

- Fact

Concept - Procedure

- Principle

t Learning Strategy

Figure 7: Example of goal visualisation with the Quail Model

First of all, notice that G6 gives here little trouble: the addressed level is that of inquiry about facts and concepts of neuroscience. Its scope is find, as it stimulates learners to look for new knowledge in this domain. Secondly, a slight distinction between G2, G3 and G4 is made evident: the former indicates the ability to describe how a single brain is (which means, getting the insight of it thanks to the concept of brain) while G3 and G4 concern definitions (of neuron and of functional area). Finally, G5 can be placed as an attitude on the level of action.

\section{Discussion: Complexity and expressive power}

The Quail Model is quite complex and requires practice in order to become a familiar tool for design. Its complexity comes from the natural complexity of human knowledge, and from the desire not to oversimplify it. Let's take some examples that illustrate that.

- "I want my students to have seen, at least once, a formal definition of the mathematical term function. I will ask them neither to repeat it, nor to understand it - just to know it exists". How could it be classified?

The mathematical definition of function could be considered as a fact of which learners should be made aware, but it sounds weird, as it is a typical defined concept, according to Gagné. Quail would describe it as a concept on the experience level: learners should consider the existence of such a concept, though they are not required to understand it or acquire it fully. 
- "I want students to see what a classic democracy is." Democracy is indeed a concept, but how can you show it? An instructor can show an instance case, and from that let students get an insight, then define a concept. Nevertheless, the goal concerns the concept as such. Quail would represent it as a concept type on the insight level: getting an idea of the concept of democracy, without reaching a complete formulation or definition.

- Procedure, attitude and learning strategy are the types that describe the result of the involvement of freedom and will with knowledge. Actually, any procedure is indeed a set of known facts, situation grasping abilities, and heuristic principles. Yet, there is a gap between learning a procedure and applying it to real situations: the decision to use it. The same can be said for learning strategies and attitudes. This is why these three types can be represented in a valid manner on any level, and in any scope. It may sound weird that a procedure can stay within the remember scope, but think of the following examples: "I want my employees to know how they should not behave in such situations". This is a procedure goal on the level of commitment (a judgment should be formulated, that the procedure is not adequate to the case).

- Quail's approach to acquired attitudes is interesting as it reveals the particular expressing power of this model. Other models simply propose a kind of outcome called attitude, but there are a number of ways in which a learner can relate to an attitude, such as knowing that the attitude "be collaborative" exists (this would be on the experience level), being able to describe it (on the concept level), value it (on the commitment level, as "being collaborative is good" or "being collaborative is dangerous") and finally actually being collaborative. Moving from the knowledge of an attitude to acquiring it is not an easy path, and is one that instruction can support - so being able to describe it is an important gain. In the same way the Quail Model represents concepts, factual knowledge and other types of learning outcomes.

Exactly as attitudes, one can know that a set of concepts exist (such as the quantum theory) on the experience level, without knowing it in detail. One can learn and solve a problem (such as a design problem this is an insight) without being able to describe the procedure and principle he or she applied (on the concept level).

Finally, notice that the area defined by the action level and the remember scope in fact is empty: any goal on the action level will be represented within the use or find scopes. 


\section{Visualising prerequisites}

The Quail Model can be simply extended in order to represent prerequisite relationships between goals using oriented arrows. Figure 8 presents prerequisites for the goals from Table in order to acquire the concepts, the fact that we have a brain must be known; in order to develop the attitude to act safely, the idea of functional areas is important.
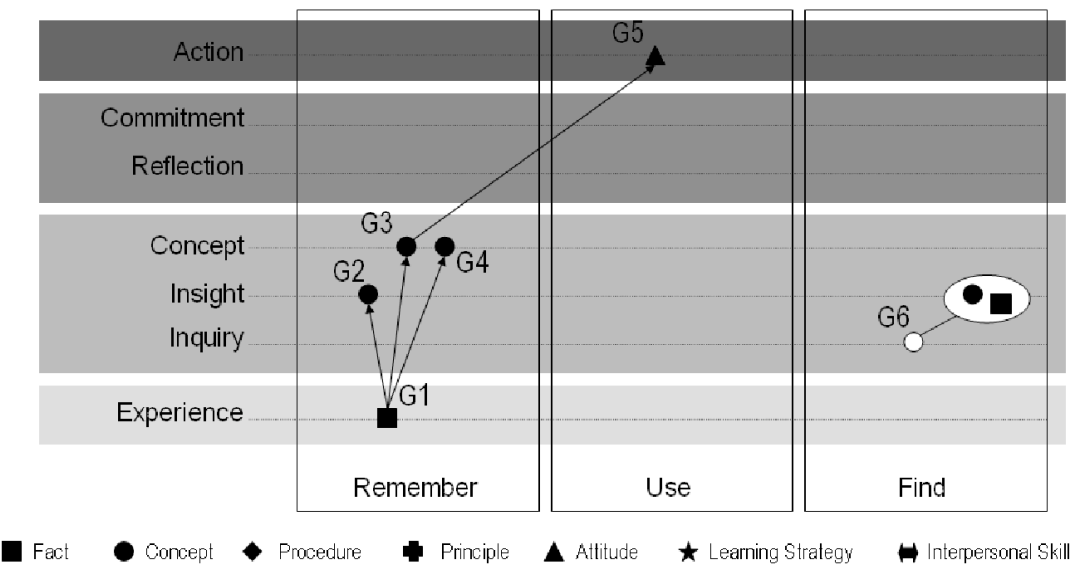

Figure 8: Example of prerequisite relationships

The next section will provide a complete example, while Section 6 will offer some elements for an evaluation of the impact of the model on design practice.

\section{Examples}

This short example is taken from the ETEC 512 course, Learning Theories, developed within an online Masters, in collaboration between Distance Education and Technology at University of British Columbia (Canada), and Monterrey Tec (Mexico). Figure 9 reports the goal statements.

In order to refine the goals, let's point out that:

1. Statement 1 groups two different goals: describe and relate.

2. Statement 3 mixes a number of different issues: analyse theories, understand them, recognise them, etc.

3. In particular, "recognise a theory in an instructional situation" in statement 3 overlaps with 4 (analyse an instructional situation). 
By the end of this course students will be able to:

1 Describe selected epistemologies of learning and relate them to the teaching - learning process.

2 Discuss major orientations leading to significant learning theories influencing instructional design theory.

3 Critically examine selected major theories of learning, recognise and apply them in instructional situations using learning technologies.

4 Use one or more theories of learning as a lens to describe, discuss, and analyse teaching and learning situations using learning technologies.

5 Use one or more theories of learning to solve given instructional design problems or approved design problems arising from the students' own situations.

6 Explain own initial philosophy / conceptions of teaching and learning

Figure 9: Initial goal statement for ETEC 512

Goals were therefore refined as in Table 2, and were mapped on the Quail Model, as in Figure 10.

Table 2: Refined goals statement for ETEC 512

\begin{tabular}{|c|l|}
\hline Tag & Statement \\
\hline A & $\begin{array}{l}\text { A1: Describe selected epistemologies of learning } \\
\text { A2: Relate them to the teaching - learning process }\end{array}$ \\
\hline B & $\begin{array}{l}\text { Discuss major orientations leading to significant learning theories } \\
\text { influencing instructional design theory. }\end{array}$ \\
\hline C & $\begin{array}{l}\text { Critically examine selected major theories of learning } \\
\text { C1: Understand them } \\
\text { C2: Evaluate them }\end{array}$ \\
\hline D & $\begin{array}{l}\text { Use one or more theories of learning as a lens to describe, discuss, and } \\
\text { analyse teaching and learning situations using learning technologies. }\end{array}$ \\
\hline E & $\begin{array}{l}\text { Use one or more theories of learning to solve given instructional design } \\
\text { problems or approved design problems arising from the students' own } \\
\text { situations. }\end{array}$ \\
\hline F & Explain own initial philosophy of / conceptions of teaching and learning \\
\hline
\end{tabular}

- A1 and C1 are concepts (epistemologies and theories of learning) on the concept level, as students are asked to know them explicitly. The scope is use, as they should be connected to real situations.

- A2 also deals with concepts as A1, but on the insight level, where concepts are to be used (the scope is use) for enlightening situations.

- B describes concepts that are simply to be remembered (major orientations), but they are on the commitment level as students are pushed to critical analysis. 


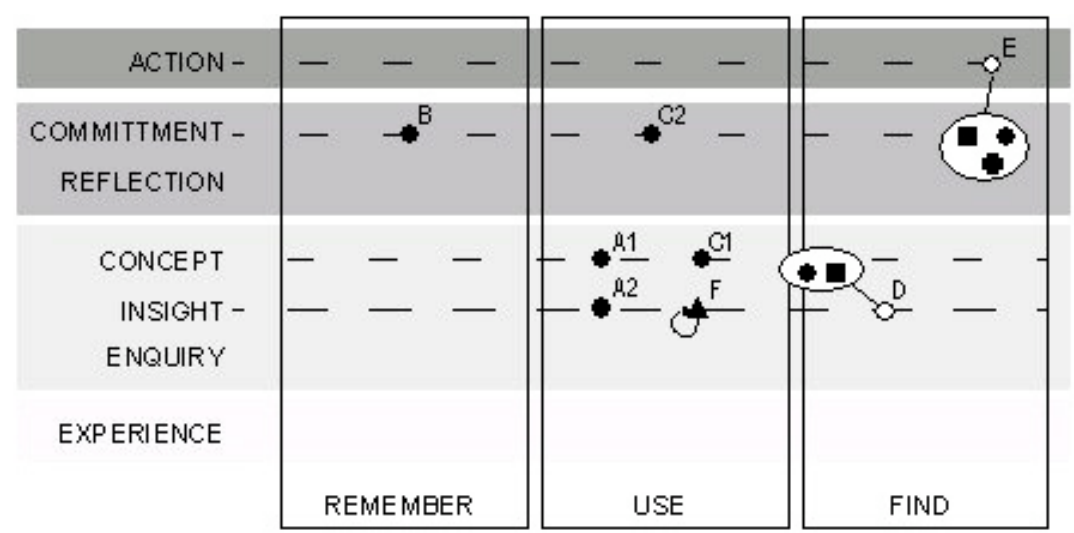

- Fact concef

- procedure - princifle 4 attmude $\star$ Learning strategr

- INTEFPESONaL SKILL

Figure 10: QUAIL goal mapping for ETEC 512

- C2 also addresses concepts (learning theories) but grasps the critical effort and is therefore on the commitment level. Its scope is use as this judgment is expected to influence the design practice.

- D is a complex goal, including concepts and facts, and is in the find scope, as it deals with the analysis of new situations. The level is that of insight, as it deals with the understanding of instance situations.

- E is a goal similar to D, but also includes design principles. It is also in the find scope, but on the action level, as the learner's design ability is here at stake.

- F finally has an attitude as knowledge object - namely, the learner's own attitude toward teaching and learning. This is why it is a selfreflective goal. It is on the insight level (each learner is concerned with her/his own attitude), and in the use scope, as this understanding should be applied in constantly observing one's own activity. This goal could have been actually also placed in the find scope, implying that once learners are aware of their conceptions, they can work on them and improve them.

\section{Feedback from real users}

\section{Who uses the Quail Model?}

The Quail Model is therefore a tool for the visualisation of learning goals but a tool for whom? 
It was specifically developed for instructional designers, ie. people who manage professionally the development of courses, instructional units or learning materials, coordinating an interdisciplinary team (instructors, tutors, technical staff, web programmers, etc). The time necessary for becoming familiar with the model and acquiring some fluency would be for them a sensible investment: the Quail Model could be a visual device for improving the shared understanding of goals within the team, and could also become a framework for developing instructional strategies, for example moving from experience to concepts, or from insights to judgments, etc. Instructors or teachers who develop their own courses are also potential users of the model.

The time spent in each process for classifying learning goals and for visualising them could be perceived as an additional cost. It is actually an investment, as it provides a shared understanding and a reliable compass for decision making: what strategy to use, what technologies to exploit for what activities, etc.

From this point of view any goal taxonomy, classification grid or visualisation device is a particular way of thinking teaching and learning, which goes beyond the "state goals" phase of the process. In this respect too, the Quail Model as a general design framework might be useful also to teachers, instructors and trainers.

\section{Feedback statements}

The Quail model was introduced as an advanced topic to two classes of South American high school teachers and professors attending a specialisation course in $\mathrm{ID}^{7}$, for a total of 64 people. They were then asked to apply the model to the definition of learning goals for one of their courses or learning units; optionally, they were also asked to provide feedback about its usefulness and practicality in a discussion forum. A response was posted by 13 teachers. Some of them had already had some instruction in ID and learning objectives.

A qualitative analysis of the collected feedback revealed that the Quail model was perceived by all respondents as an interesting and useful tool. In particular they described it as "easy to understand" and "important for team work".

Two teachers pointed out the "completeness" of the model: they felt that the Quail model offers "a deep insight of what objectives are - it is not limited to answers to who-what-why questions, but there are a wider

${ }^{7}$ The program was organised by Eurocol - http:/ / www.eurocol.edu.co/ 
number of factors to consider - such as the inquiry... and the verification of the teachers' proposal."

Moreover, the teachers indicated that the model "allows thinking globally to instructional activities", keeping all goals in mind, and that it "allows a simplification and clarification of goals", making them unambiguous and easy to share. Moreover, the teachers felt comfortable with the fact that "it stresses the importance of starting from experience" - a basic element of teaching confirmed by their own professional experience.

Some teachers pointed out that, although easy to understand, the model requires some practice: "it requires not only optimal competence with the topic you are working on..., but also optimal competence with the model itself, as it is very demanding in placing objectives on the grid".

\section{Conclusions: Summary and outlooks}

After a short review of different models for the definition and classification of high level learning goals, this paper presented a novel visual tool, which integrates more traditional instructional design approaches with insights by Lonergan. The Quail Model is a visual tool developed as a support for the discussion about learning goals within a course design team. The implications underlying the model were discussed, and its expressive power tested with some examples.

This research is but initial: the Quail Model needs to be further refined through the collection and analysis of case studies, and its impact on the design practice should be evaluated in the long term and with different disciplines and school levels. Moreover, the possibility to produce an application to support the creation of visuals is a key element for making the model usable and appealing to practitioners ${ }^{8}-$ this is a topic that has been up to now inexplicably marginal in instructional design.

An interesting area to investigate is the integration of affective issues along with cognitive ones, merging even more the two original domains by Bloom.

Finally, as long as it conveys a way of conceiving education, a model like Quail might raise some interesting issues for the development of learning technologies in their broad sense. For example: How can technologies broaden the experience of learners, e.g. with simulations or 3D worlds? Do

${ }^{8}$ A Flash demonstration application can be freely downloaded at

http: / / www.istituti.usilu.net/ botturil/web/e2 ml/ quail.htm 
these methods actually improve the understanding and conceptualisation of experiences? Can multimedia application support the generation of mental images? How to effectively support the generation of insights and judgments?

The perspective under which the Quail Model was developed and should be used considers teaching like painting or playing music. These skills can be acquired, and experience enhances the performance, but a good teacher, like the painter or the musician, is natural born: learning and practicing can bring improvements, but only if rooted in the fertile soil of natural aptitude. If we can hope to have (or to be) naturally talented teachers, what can be learnt? Specific knowledge, examples of best practices and common mistakes, and tools that improve the performance. The Quail Model belongs to the tools that the instructional designer can use for improving her/his performance.

\section{Acknowledgments}

This paper, and the research work that produced it, owe much to Francesco Botturi (Università Cattolica di Milano, Italy), who introduced me to the work of Bernard J. Lonergan, and to Moira Carley (Lonergan College, Concordia University, QC), who guided and supported me in working on Lonergan's texts.

Special thanks also to Rick Kenny (Athabasca University, AL), who completed my introduction to Instructional Design and provided me with up-to-date references. Thanks also to Bridget Cooper (University of Leeds, UK) for her appropriate feedback.

\section{References}

Anderson, L.W. \& Krathwohl, D.R. (2001). A Taxonomy for Learning, Teaching and Assessing. A Revision of Bloom's Taxonomy of Educational Goals. New York: Addison Wesley Longman.

Bloom B.S., Krathwohl, D.R. et al. (1956). Taxonomy of Educational Goals: The Classification of Educational Goals, by a committee of college and university examiners. Handbook I: Cognitive Domain. New York: Longmans, Green \& Co.

Bloom B.S., Krathwohl, D.R. et al. (1964). Taxonomy of Educational Goals: The Classification of Educational Goals, by a committee of college and university examiners. Handbook II: Affective Domain. New York: Longmans, Green \& Co.

Bruner, J.S. \& Goodman, C.C. (1947). Value and need as organizing factors in perception. Journal of Abnormal and Social Psychology, 42, 33-44. 
Bruner, J.S. \& Goodman, C.C. (1949). On the perception of incongruity: A paradigm. Journal of Personality, 18, 206-223.

Dick, W. \& Carey, L. (2001). The Systematic Design of Instruction. 6th ed. New York: Harper Collins College Publishers.

Gagné, R.M., Briggs, R. \& Wager, W. (1992). Principles of Instructional Design. 4th ed. Orlando, FL: Harcourt Brace Jovanovich.

Gagné, R.M. \& Merrill, M.D. (1990). Integrative goals for instructional design. Educational Technology Research and Development, 38(1), 23-30.

Gagné, R.M. (1985). The Conditions of Learning. 4th ed. New York: Holt, Rinehart \& Winston.

Harrow, A. (1972). A Taxonomy of the Psychomotor Domain. A guide for Developing Behavioral Goals. New York: McKay.

Lee, B.N. \& Merrill, M.D. (1972). Writing Complete Affective Goals. A Short Course. Belmont, CA: Wadsworth.

Lonergan, B. (1957). Insight: A Study of Human Understanding. London: Longmans, Green and Co. and New York: Philosophical Library.

Lonergan, B. (1980). A Post-Hegelian Philosophy of Religion. [Lecture at the 14th Congress of the International Association for the History of Religions,

Winnipeg, Canada, August 17-21]. Quoted in: Doran, R.M. (1990). Theology and the Dialectics of History. Toronto: University of Toronto Press, 1990.

Lonergan, B. (1988). Cognitional Structure. In F.E. Crowe \& R.M. Doran (Eds.), Collected Works of Bernard Lonergan (vol. 4, Collection). Toronto: University of Toronto Press.

Lonergan, B. (1990). Understanding and Being: The Halifax Lectures on Insight. Toronto: University of Toronto Press [edited by E.A. Morelli \& M.D Morelli].

Merrill, M.D. (1994). Instructional Design Theory. Englewood Cliffs, NJ: Educational Technology.

Merrill, M.D. (1983). Component Display Theory. In C.M. Reigeluth (Ed),

Instructional-Desion Theories and Models: An Overview of Their Current Status (vol. 1, pp. 279-333). Hillsdale, NJ: Lawrence Erlbaum Associates.

Luca Botturi
NewMinE Lab - New Media in Education Laboratory
Università della Svizzera italiana
Via Giuseppe Buffi 13, CH-6900 Lugano, Switzerland
Email: luca.botturi@lu.unisi.ch Tel: +41 919124722 Fax: +41919124647
http:/ / www.newmine.org/




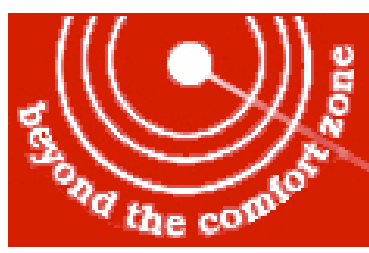

\title{
ASCILITE 2004
}

The University of Western Australia

\author{
5-8 December 2004
}

http://www.ascilite.org.au/conferences/perth04/

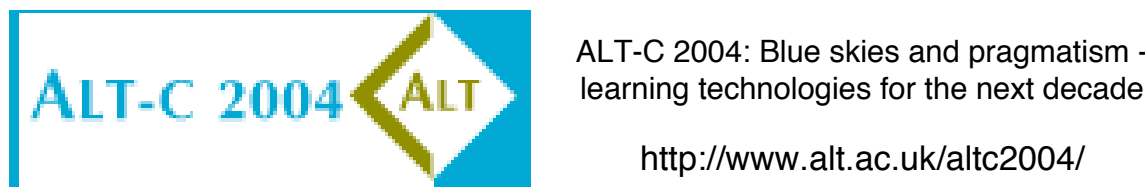

11th International Conference of the Association for Learning Technology, University of Exeter, England, 14-16 September 2004 